\title{
Why Should Natural Principles Be Simple?
}

\author{
Arturo Tozzi ${ }^{1}[$
}

Received: 6 January 2021 / Accepted: 10 March 2021 /

Published online: 16 April 2021

(C) The Author(s), under exclusive licence to Springer Nature B.V. 2021

\begin{abstract}
One of the criteria to a strong principle in natural sciences is simplicity. The conventional view holds that the world is provided with natural laws that must be simple. This common-sense approach is a modern rewording of the medieval philosophical/theological concept of the Multiple arising from (and generated by) the One. Humans need to pursue unifying frameworks, classificatory criteria and theories of everything. Still, the fact that our cognitive abilities tend towards simplification and groupings does not necessarily entail that this is the way the world works. Here we ask: what if singularity does not pave the way to multiplicity? How will we be sure if the Ockham's razor holds in real life? We will show in the sequel that the propensity to reduce to simplicity the relationships among the events leads to misleading interpretations of scientific issues. We are not going to take a full sceptic turn: we will engage in active outreach, suggesting examples from biology and physics to demonstrate how a novel methodological antiunitary approach might help to improve our scientific attitude towards world affairs. We will provide examples from aggregation of SARS-Cov-2 particles, unclassified extinct creatures, pathological brain stiffness. Further, we will describe how antiunitary strategies, plagiarising medieval concepts from William od Ockham and Gregory of Rimini, help to explain novel relational approaches to quantum mechanics and the epistemological role of our mind in building the real world.
\end{abstract}

Keywords Neuroscience $\cdot$ COVID-19 $\cdot$ Dickinsonia $\cdot$ Sphere packing $\cdot$ Relational quantum mechanics

"Natural principles must be simple". Motivated by Hilbert's 24th problem, Hipolito (2019) suggests that the Free Energy Principle (Friston, 2010) takes a seemingly mathematical complex domain and must be reduced to something simple. The author follows the common belief that the world must be fitted with

Arturo Tozzi

tozziarturo@libero.it; arturo.tozzi@aslnapoli2nord.it

1 Center for Nonlinear Science, Department of Physics, University of North Texas, 1155 Union

Circle, \#311427, Denton, TX 76203-5017, USA 
unifying natural laws and that the simplicity of a model is relevant to estimating inductive inference, predictive accuracy and explanatory power (Goodman, 1959; Foster \& Martin, 1966. Akaike, 1973; Forster \& Sober, 1994; Harman, 1999; Baker, 2003). This approach is a reminder of ever-present medieval hints from ancient scholastics (Oreskes et al., 1994), such as the Ockham's razor and the Neoplotinian tenet that the Multiple must be generated from (and by) the One. Here we ask: why there must be unifying laws? Why do we need theoretical simplicity, either syntactic (i.e., simplicity) or ontological (i.e., parsimony)? In touch with set theory, observers tend to build various arbitrary sets which do not necessarily stand for different objects or events (Friedman, 1974; Tozzi \& Peters, 2020a). Our biggest problem is perhaps the mental way we cope with everyday life using analogy, i.e., the common-sense identity of relation between apparently unrelated objects or features (Hesse, 1974; Chater, 1999; Sowa \& Majumdar, 2003). Through analogy, our brain tries to make sense of the unpredictable features of the ceaseless environmental inputs (Hofstadter and Sander, 2011; Koczkodaj et al., 2017). Yet, Mc Ginn's cognitive closure (McGinn, 1994) suggests that our intrinsically limited minds are prevented to know the reality subtending our perceptions. Think to the Wittgenstein's lion, or the Nagel's bat, or to medieval theologians who gave for granted that God must exist just because the most of humankind believes in God. Since the times of Hermes Trismegistus, countless scholars (both philosophers and scientists) have been used to proceed from the One to the Multiple and to justify the Ockham's razor (Barnes, 2000; Kelly, 2004).

Still, some authors disagree. For example, Ackerman (1961) and Bunge (1961) challenge the role of simplicity in inductive inference and the justifiability of simplicity criteria in theory evaluation. In Alain Badiou's opinion, the One is just an operation on a subtending manifold, since the Multiple gives rise to the One, and not vice versa (Badiou, 1888). This approach rejects the classical approach: God $\rightarrow$ Multiplicity, then One/Simple $\rightarrow$ Multiple/Complex. Likewise, Deleuze and Guattari (1980) introduced a theory of a unity that is multiple in itself. They point towards non-hierarchical connections opposed to the treelike conceptions of knowledge based on dualist categories and binary choices. Apart from the above-mentioned philosophical issues, things are not as simple as believed also in mathematics. It is remarkable that the same Hilbert was puzzled by Godel's and Tarki's theorems which prevented his efforts towards simplicity and unification of mathematical foundations. Since the One is generally believed as infinite, and since a mathematical infinite can be a multiple of another (Tozzi \& Peters, 2020b), we may state, together with the medieval thinker Henry of Harclay, what follows: the fact that we humans are able to think to infinity and to the One does not scientifically imply that infinity and the One really exist in the Universe (Sylla, 1998a, 1998b). We will show in the sequel that the attitude towards simplicity leads to misleading interpretations of scientific issues. Despite our destructive criticism, we are not going to take a sceptic turn. Indeed, our aim is to show how antiunitary methodological approaches shed light on fully underrated features. 


\section{Against Ochkam's Razor: Physical and Biological Account}

In quantum dynamics, the demarcation problem and the failure of the principle of locality cause severe troubles to the otherwise untouchable Aristotelian principle of identity (Tozzi \& Peters, 2018): if A does not anymore equal A, how could the Unity and the Simple be defined? To make things even worse, the quantum field theory describes the Universe as permeated by at least 24 fields (possibly more), each one corresponding to a single elementary particle: too many to be reduced to Simplicity. If the Universe is suffering a progressive quantum decoherence and decrease in number of symmetries, this means that there must have been at the beginning something very symmetric, therefore overly intricate and complex. Obviously, this not compatible with the concept of One preceding the Multiple.

At times, straightforward phenomena can be more puzzling than believed. To provide a baffling example, hot water freezes faster than cold water, as suggested by the temperature dependent Mpemba effect. Counterintuitively, a hot system can be cooled faster that an identical system initiated at a lower temperature. How do we explain this anomalous behaviour? In this case, a unifying principle cannot save us. In nonequilibrium thermodynamic systems, the energetic state closer to the ground state may take a longer time to reach the lowest energetic basin (Lu \& Raz, 2017). See Fig. 1 for further details. This means that, under the proper conditions, a cold system can heat up faster than the same system initiated at a higher temperature. This also means that the mechanisms underlying the Mpemba effect requires a complex explanation which casts doubt on the existence of a sole subtending principle.

Then comes biology. Life is not reducible to simplicity: just looking at the intricate patterns of the plots and tables illustrating cellular metabolic pathways, it is self-evident that things are not simple at all. The same limitation holds for the very concept of evolution: the demarcation among living beings is somewhat arbitrary. Our concept of species is very unacquainted since the borders among living beings are often not experimentally proven. One of the most typical examples is the enigmatic Dickinsonia, an extinct lineage that does not fit within known animal phyla. Dated about 571-541 million years ago, it is a marine genus of fossils belonging to the early communities of Ediacara Biota, i.e., the oldest fossil evidence for the appearance of animals (Ivantsov, 2007). Tentatively assigned to the animal kingdom (Bobrovskiy et al., 2018), the mobile Dickinsonia lacks convincing evidence of mouth, gut and anus and possibly fed via external absorption and digestion of organic matter through its ventral surface. We classify Sapiens, Neandertals, Denisovans, Floresiensis as distinct species of the genus Homo, despite genetic studies point towards multiple ancient hybridizations (Gibbons, 2017; Slon et al., 2018; Massilani et al., 2020). Concerning our DNA, species demarcation is at times difficult, due, e.g., to the occurrence of viral and bacterial sequences in animal genomes. The horizontal transmission and lateral transduction of genetic material described by Chen et al. (2018) and D’Angiolo et al. (2020) may overtake the canonical "species-specific" barriers, making it difficult to sharply incorporate individual beings in the framework of a single species. We may state that horizontal transmission of genetic material makes evolutionary trajectories of living beings unpredictable and 


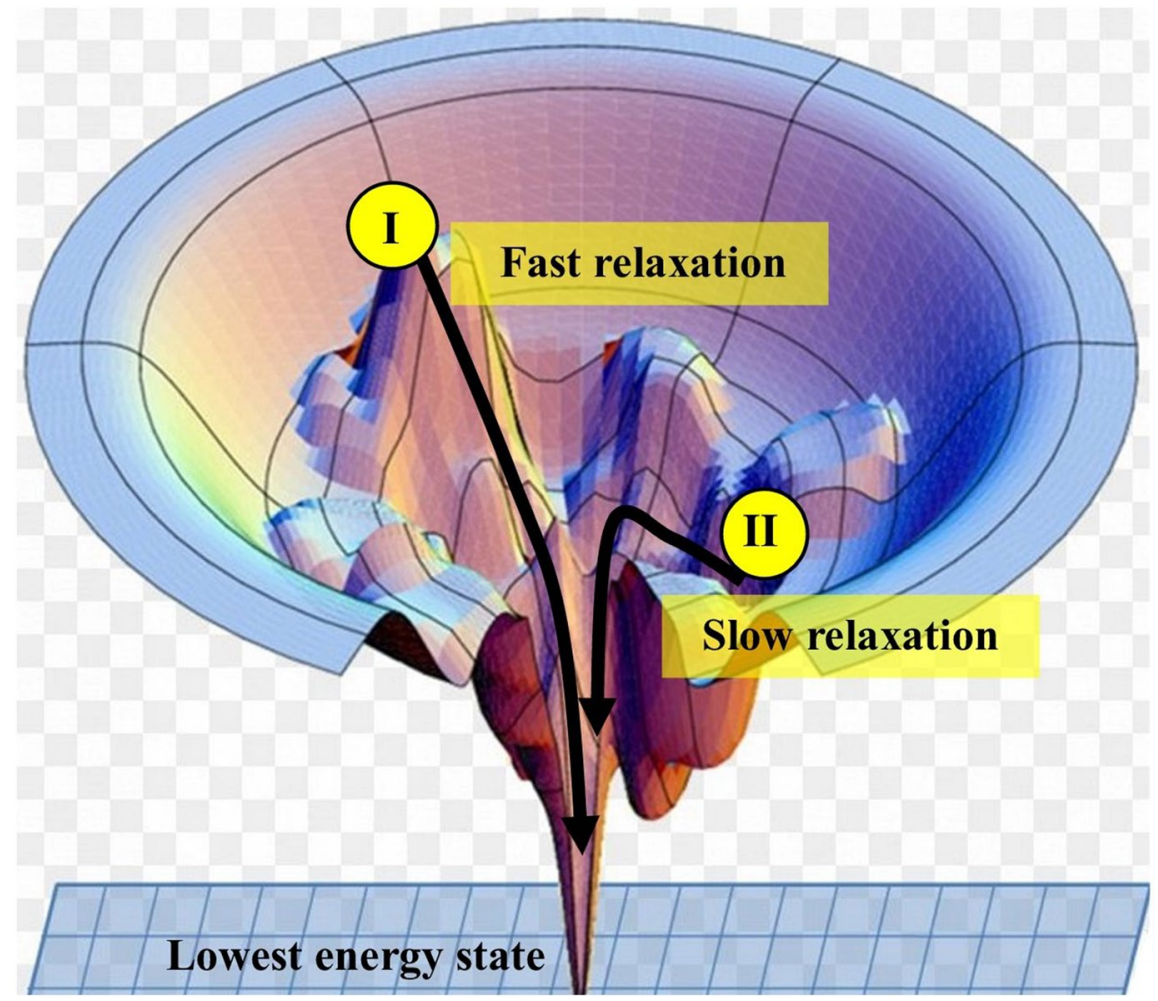

Fig. 1 Potential energy basin of water cooling explain the Mpemba effect. The hotter point of departure (yellow circle I) takes less time to reach the freezing temperature (termed: lowest energy state) compared with the colder point of departure (yellow circle II)

irreducible to the One, in touch with Deleuze and Guattari's model (1980). The very concept of the evolutionary life proceeding from monocellular to multicellular beings could be misleading. Indeed, recent studies star to unveil a more complicated state of affairs... see Bhowmik and Krishnamurthy (2019).

\section{The Scientific Virtues of Methodological Antiunitary Approaches}

Here we show how the switch from one-to-multiple approaches to antiunitary methodology might contribute to unravel intriguing scientific conundrums. For example, a question has been raised during these frantic months of pandemics: why do elder people suffer from more severe COVID-19 symptoms compared with children (see, e.g., Parri et al., 2020; Qiu et al., 2020)? Despite attempts at explanations generally focus on the foremost role of the spike protein, our approach suggests to look for underrated issues. SARS-Cov-2 particles are not just made of RNA and viral proteins (Chen et al., 2020), but also of a lipid wall "stolen" from the endoplasmic reticulum-Golgi intermediate compartment (ERGIC) of the human host (Brian 
\& Baric, 2005; Appenzeller-Herzog \& Hauri, 2006). After intracellular assembly, virions are transported to the cell surface and released by exocytosis (Risco et al., 2002; Risco et al., 2002) (Fig. 2a). It is well documented that biochemical, morphological and functional modifications of ERGIC membranes occur at different ages and during senescence (Cho et al., 2011; Torres-González et al., 2012; Brown \& Naidoo, 2012; Udono et al., 2015; Calvo-Rodríguez et al., 2016; Liu et al., 2018; Su et al., 2018; Janikiewicz et al., 2018; Despres et al., 2019; Chadwick \& Lajoie, 2019). This means that SARS-Cov-2 changes its "skin" when jumps from old to young hosts and vice versa. Since human ERGIC membranes display different arrangements with time passing, the SARS-Cov-2 particles produced in the tissues of children are phenotypically different from the particles produced in the tissues of elder people (Fig. 2b). The different features of SARS-Cov-2 emerging from old and young cells might contribute to variations in viral load, infectivity and clinical severity.

The intrinsic impossibility to reduce functional affairs to unifying, antiunitary principles is self-evident also in neuroscience. Recent claims suggest that the brain activity takes place in multidimensional phase spaces. For a review, see Tozzi (2019). When I see a cat in front of me, I perceive not just the three-dimensional image of the cat, but also countless mental features of the cat (emotional features: "how tender!", cognitive features: "this is a Feline", linguistic features, and so on). In other words, we (quite improperly) use the same word "cat" to describe both the real perceived animal and the imagined animal. Incidentally, another existential quantifier would be required in logic to discern between the object and its mental image. The common belief is that biophysical phenomena take place in Euclidean phase spaces (Bellmund et al., 2018). Still, recent work has shown that the appropriate isometric space for embedding complex networks (in particular the neural multidimensional phase space) is not the flat Euclidean space, but rather negatively curved hyperbolic spaces (Sengupta et al., 2016; Chamberlain et al., 2017). Embeddings in hyperbolic spaces outperform Euclidean spaces since they allow a more manageable treatment of the required thermodynamic equations, such as, e.g., the Fokker-Plank equations (Sengupta et al., 2016).

The current paradigm in neuroscience is framed on a basic unitary principle: the brain activity can be explained in terms of the action potentials and the nervous circuits which generate the electric spikes crossing the central nervous system. However, recent insight point towards the brain activity (including cognitive functions) as mediated not just by spikes, but also by a countless number of other heterogeneous factors such as macromolecules, transitory changes in protein conformation, glial cells, extracellular matrix, peripheral receptors, substrate patterning, intestinal bacteria, immune system, prion-based mechanisms, metabolic status, nutritional factors, hormones breathing, heartbeats, light, and so on. For a review, see Tozzi (2015). Here we suggest that another still unexplored issue might contribute to modify the brain activity, i.e., a correlation between rheology and neurological disease. It is well-known that electromagnetic waves propagate more slowly and with lower frequencies when traveling through more liquid mediums (Ogilvie \& Proctor, 2003). Concerning the viscoelastic properties of the brain tissue, differences in stiffness among dissimilar neural structures and areas have been described (Budday et al., 


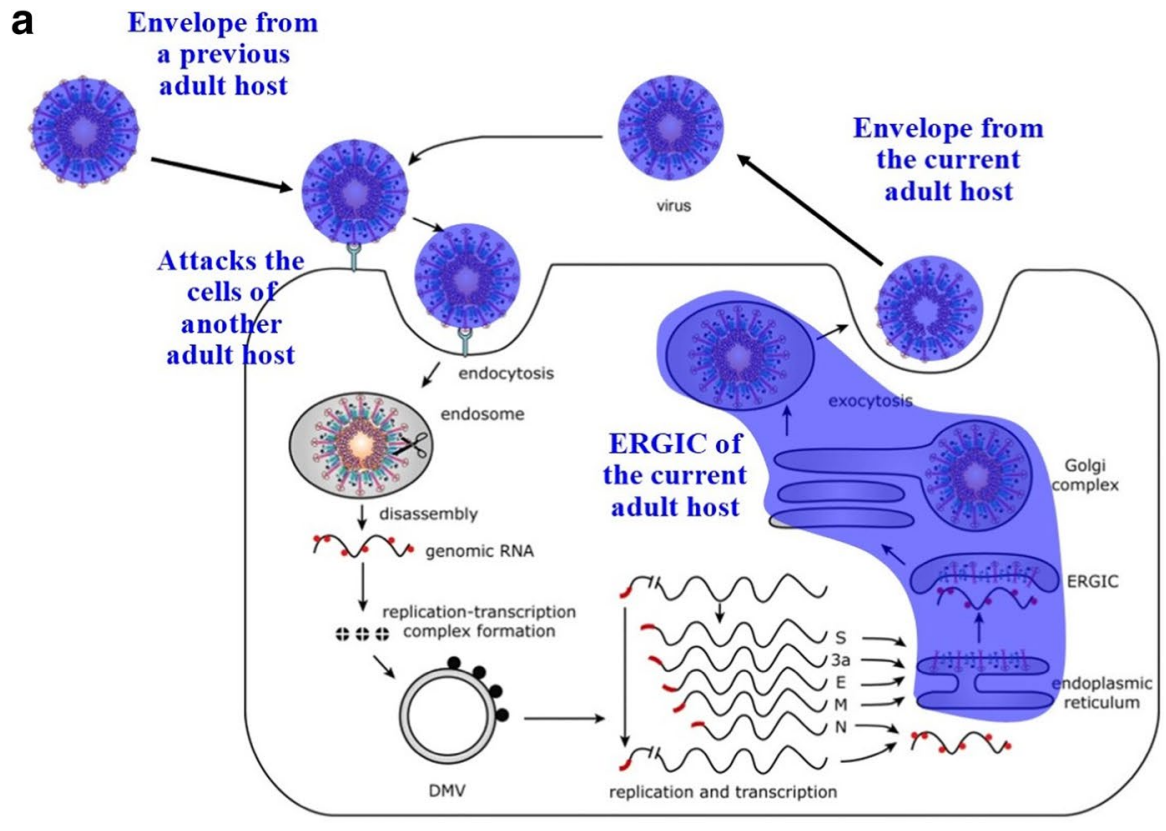

b

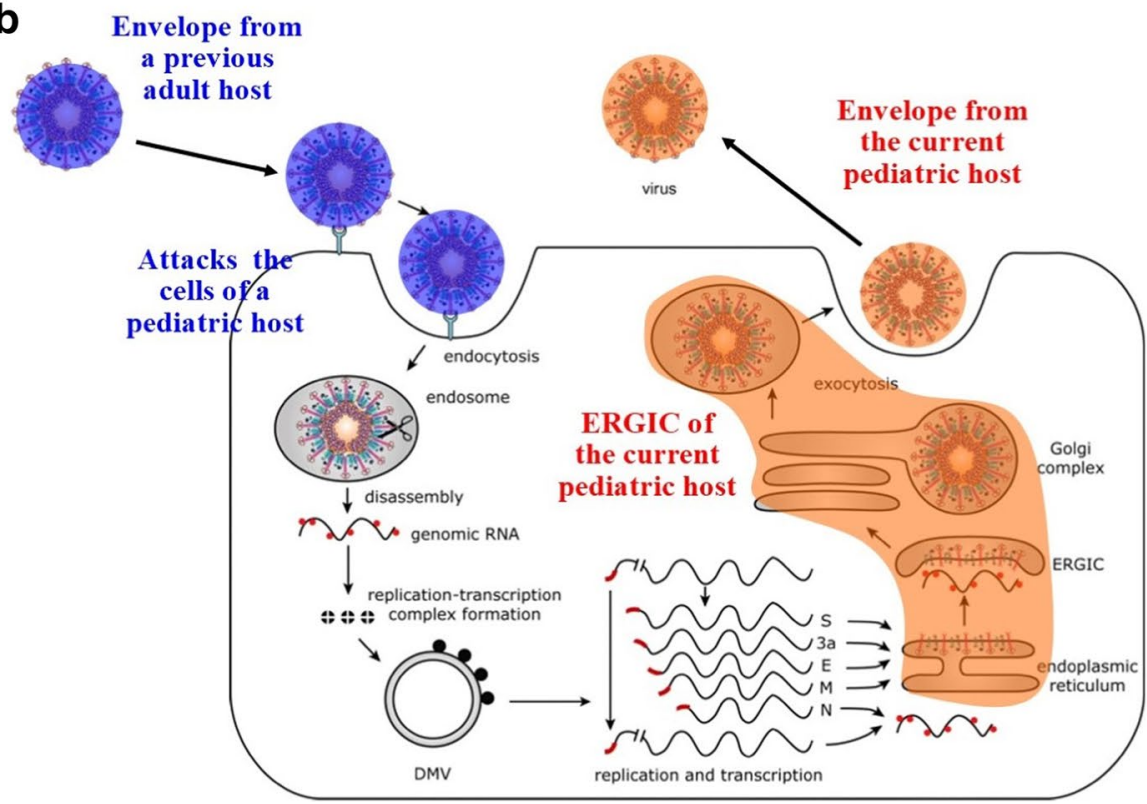

Fig. 2 Replication pathway of SARS-Cov-2. The ERGIC of the adult host's cell, painted in blue (a), is different from the ERGIC of the child host's cell, painted in red (b). This means that the virions released by elder host cells (blue spheres) are phenotypically different from the virions released by young host cells (red spheres). Modified from: de Haan and Rottier (2006) 
2017; Ranta et al., 2017; Miceli et al., 2017): in particular, decreased stiffness and viscosity can be detected in patients with clinical diagnosis of Alzheimer's disease (AD) and several dementia subtypes (Murphy et al., 2011; ElSheikh et al., 2017; Gerischer et al., 2017; Del Giudice et al., 2017; Shamaev \& Shumilova, 2018). Furthermore, $\mathrm{AD}$ is characterized by significant increases in slow wave EEG activity in different brain areas (Waninger et al., 2016). This might mean that the decreases in brain stiffness occurring in $\mathrm{AD}$ can be correlated with the experimentally detected pathological decline of EEG frequencies. We speculate that two different regimes of brain electric oscillations take place: the healthy brain tissue displays higher values of viscoelastic indexes and encompasses higher EEG frequencies, while the AD brain tissue displays a more liquid behavior and encompasses lower EEG frequencies. This would pave the way to the use of drugs such as mannitol (Shaltiel-Karyo et al., 2013), hyaluronic acid and osmolytes to restore the impaired brain viscoelastic features in AD.

In physics and biology, a foremost issue testifies that the relationships between the one and the multiple are more intricate than suggested by the plain and reassuring account of the Ockham's razor. Nonlinear dynamics, single-parameter bifurcations, random graphs, complex and/or chaotic systems prove that things and facts are not as simple and predictable as believed until half a century ago. In touch with this observation, Turalska and West (2018) made an astonishing achievement, demonstrating that the Mittag-Leffler equations are able to describe the movements of a single component belonging to a collective system. In touch with Bechtel's multilevel emergentism (2008), this confirms how higher systemic levels modify the dynamics of the lower ones and vice versa, causing an intermingling of the One and the Multiple that cannot be resolved by a trivial reduction to the One and to the Simple.

Here you are a biological example of emergence from aggregation, against too strict holistic approaches based on the First Principles. Viruses may spread not just as single particles, but also as collective aggregates reminiscent of bacterial biofilms (Segredo-Otero \& Sanjuán, 2019; Millen et al., 2019; Thoulouze \& Alcover, 2011; Andreu-Moreno \& Sanjuán, 2020; Leeks et al., 2019). For example, close evaluation of available microscopic photographs and videos of SARS-CoV-2 virions shows that their round particles squeeze and stick into each other (Fig. 3a), progressively aggregating in small clusters that fill the available liquid space (Fig. $3 b$ ). It could be boosted by the fact that the spike proteins can be tilted by up to $\sim 90^{\circ}$ relative to the membrane, giving their head an unexpected orientational freedom (Watanabe et al., 2020; Ke et al., 2020; Turoňová et al., 2020). In the extracellular milieu, viral particles tend to aggregate in interconnected globular networks of progressively growing assemblies (Fig. 3c-d). The possibility to achieve collective dynamical behavior may provide invaluable advantages to SARS-CoV-2, such as, e.g., best sphere packaging and inner core sanctuary spared by immunologic and environmental noxae (Fu et al., 2016; Teich et al., 2016). In sum, virionic clusters might stand for an unnoticed collective mechanism that on one hand contributes to viral spread, on another hand stands for a potential target leading to novel antiviral strategies. 
a
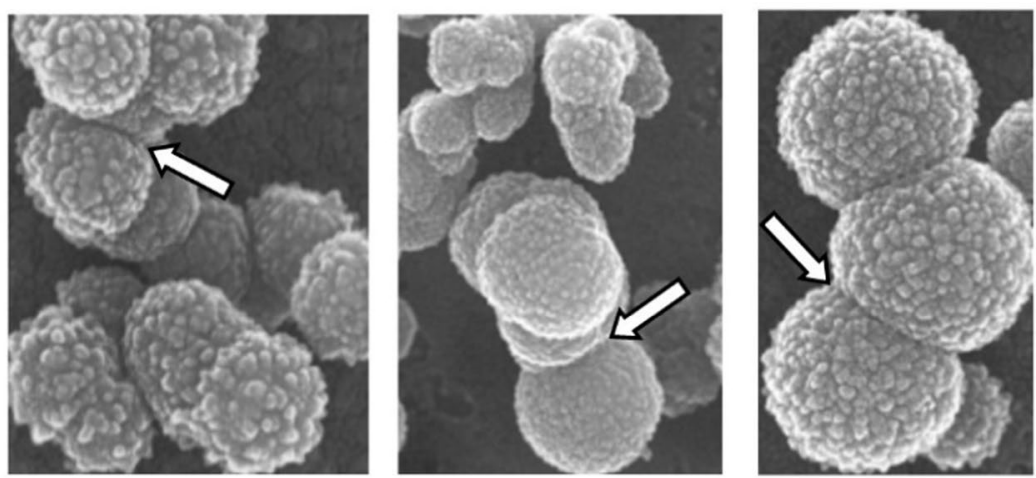

b
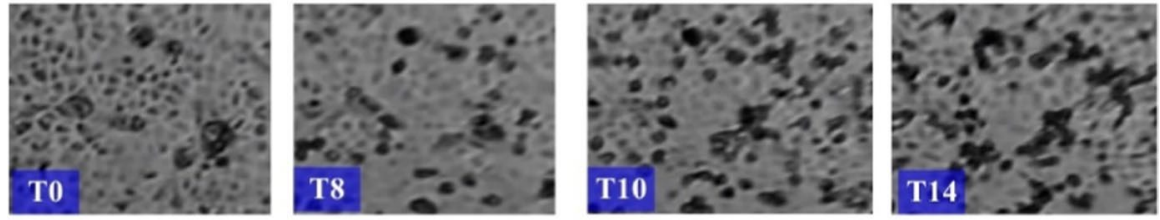

C

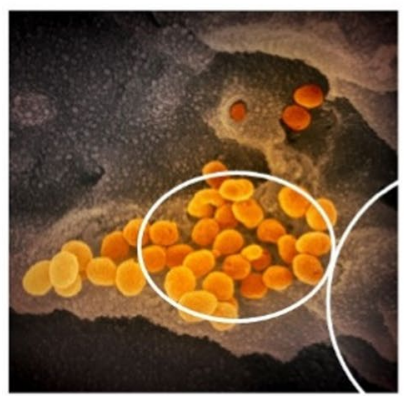

d

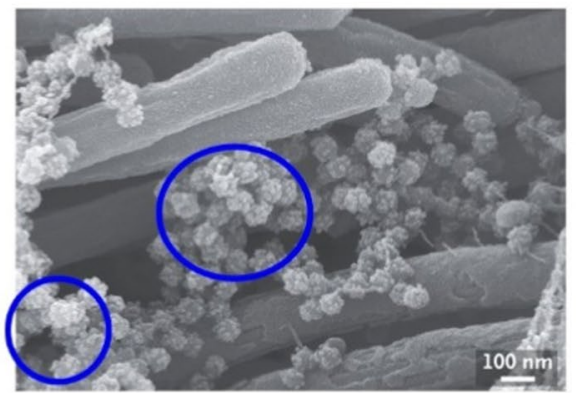

Fig. 3 Interaction of coronavirus particles detected by transmission electron microscope at different magnifications. a. SARS-CoV particles have been found either isolated or in aggregates. The arrows highlight the adhesion areas between different squeezed virions. Modified from Lin et al. (2004). b. Movie frames illustrating the temporal outcome of SARS-CoV-2 virion production and growth in the supernatant of infected cultured cells. Modified from: https://www.youtube.com/watch?v=qTt3P5V8M1A\&featu re=youtu.be. Note the progressive crowding of virion particles: this leads small clusters to converge in bigger clusters. c. SARS-CoV-2 virions emerging from the surface of infected cultured cells. Small clusters tend to converge, giving rise to larger aggregates (round shapes). Modified from: https://www.flickr. com/photos/niaid/albums/72157712914621487. d: spreading of SARS-CoV-2 inoculated into human bronchial epithelial cells (modified from Ehre, 2020)

\section{Conclusions}

Every science is based on the available knowledge related to its own specific content. Progress is pursued through a progressive accumulation of conclusions, making 
us closer to the subtended unifying principles. This standard way to think and proceed was endorsed also in pre-scientific eras: think, e.g., to Thomas Aquinas, who maintains that every science is a single and simple habit of the intellect, consisting of the unity of its formal object. To provide another example, Peter Auriol, answering to the question: "whether the habit acquired from theological study be one of many?" states that science is ONE habit of the intellect, generated by sequentially acquired demonstrations (Spade, 1972). We make progress from one conclusion to another, since every conclusion sheds light on the middle terms of the syllogism and improves the knowledge of other conclusions. Science is the science of the conclusions, and conclusions allow us to mentally grasp the underlying principles, i.e., the first truths. A single act of the intellect simultaneously grasps the truth of the principle and the truth of the conclusion.

Despite our severe critique of his razor, Ockham's philosophy could still make a huge contribution to this debate. Ockham is notorious just for his Razor, as Ravel is notorious just for his Bolero, despite their (scientific and musical) output is overwhelmingly rich of almost forgotten treasures. To unravel the freshness of Ockham's thought, we will start from an epistemological account of quantum mechanics. Quantum mechanics has been interpreted by influential scientists as a referenceframe theory pertaining to observer-dependent relational properties (Smerlak \& Rovelli, 2007; Yang, 2018). Relational formulations of quantum mechanics have been experimentally supported by recent papers that contradict the tenets of local realism (The BIG Bell Test Collaboration, 2018; Proietti et al., 2019), the same local realism which states that: "the properties of the physical world are independent from the observer". In the fascinating Wigner's friend paradox, John is sealed in a lab and measures a particle, while Nicholas stands outside. Suppose that John is entangled with Nicholas in such a way that they perceive that the particles they measure are correlated. According to quantum mechanics, particles are allowed to occupy both John's and the Nicholas' locations at once, i.e., they are superimposed. However, when John observes his particle, the same act of observing "collapses" the particle to just one spot, so that John detects the two particles as not anymore superimposed. Yet for Nicholas the superposition remains: he will detect the collapse occurring when he will make a measurement of his own particle sometime later. This means that John's and Nicholas' experiences are frankly conflicting. The Wigner's friend paradox, once believed to be just an exotic gedankenexperiment, has been recently experimentally challenged. Bong et al. (2020) found, again, an irreconcilable mismatch between John's and Nicholas' observations. Their conclusions were that the unitary, deterministic evolution of isolated systems and the non-unitary, probabilistic state update after a quantum measurement are hard to reconcile at all coarse-grained scales, including the macro-scales of the observers. Therefore, the slogan "every observed event exists absolutely, not relatively" could be physically erroneous.

Here a philosophical concept from our medieval past comes into play and might help to solve the conundrum. In the question 19 of the second quodlibet, William of Ockham asks whether the proposition "hoc est corpus meum" ("this is my body") is literally true as uttered by the priest at mass (Ockham, 1991). According to Ockham, to every spoken proposition corresponds some mental proposition. When the priest utters the first words "hoc est", the body of Christ 
does not exist yet in the Eucharist, because the words "hoc est" are not themselves determinate enough to fix the meaning intended by the speaker. Indeed, the priest's utterance in the middle of the phrase is true as mental proposition, but it is not yet true as spoken proposition, because the subsequent words "corpus meum" have not yet been pronounced. According to Ockham, a mental proposition is true at the beginning and at the end, because it exists as a whole all at once. This means that a mental proposition can be termed "ens permanens" (a permanent entity). In turn, a spoken proposition exists just successively and not all at once, so that it is true at the end but not at the beginning of the utterance. This means that a spoken proposition can be termed "ens successivum" (a successive entity). The spoken proposition is not true at the beginning, rather it is true at the end of the utterance. Coming back to relational quantum mechanics, we may state that reality itself is different at the beginning and at the end of the utterance, or, in non-linguistic setups, we may state that reality itself is different at the beginning and at the end of the experimental procedures to detect quantum phenomena. To provide an example, at the beginning of quantum entanglement measurements nobody knows which quantum state will be detected after the experiment has been performed. Quantum reality stands for an ens successivum such that only a part of it exists at any given time.

A further leap is required to proceed towards a novel epistemological approach to quantum mechanics: from relationism to interactionism. This means that the role of time, underrated and almost despised in quantum mechanics (Moreva et al., 2014), must be kept into account, since a deep difference does exist inside a quantum state before and after the observer's measurement. To move onwards, we are required to go back to Gregory of Rimini and his theory of complexe significabile (Zupko, 1994). Gregory of Rimini suggests that the intuition of a preposition and the comprehension of its meaning are two different mental acts (Dal, 1956). The subject who agrees to a scientific issue does not keep into account the proposition or its conclusion, rather he keeps into account what does the proposition mean, or its truth (sic esse vel sic non esse). The simple apprehension and intuition of a proposition are not yet scientific knowledge, the latter requiring intensionality and agreement: you do not need water as it is, rather you need water because you are thirsty. Therefore, the object of the scientific knowledge does not consist of the simple demonstration, rather it consists of the total (unitary) meaning of the conclusion independent of the same proposition. The object of the scientific knowledge is termed "complexe significabile", i.e., the "that clause" introduced by the Oxonensis Adam of Wodeham and exported by Gregory to the University of Paris (Nannini, 2015). "Homo est albus" stands neither for "homo", nor for "albedo", rather it stands for a total meaning which is different from both real objects and mental entities. "Homo est albus" becomes a distinct entity, separate from the subject "homo" and the predicate "est albus", since it does match neither the "homo", nor "est albus". Therefore, the object of scientific knowledge becomes the mental process of agreement to the possible true meanings.

Gregory's complexe significabile was condemned in 1277 by the scholars of the University of Paris, because they reputed his approach unnecessarily expanding the eternal truths: to provide an example, the phrase "the Father is correlated with the 
Son" might point towards something different from the Father and the Son. Leaving apart Gregory's ultimate output concerning divine realities, we may state, in fully agreement with him, that the activity of the human mind produces fictious entities. For in the end our mental activity increases the number of entities, so that our subjectivity multiplies concepts by default. If such entities and concepts are real of fictitious, it does not matter anymore: what counts is that the possible meaning of a proposition becomes the real meaning in relational quantum mechanics.

Acknowledgments The Author would like to thank Vittorio Tozzi, M.D., Ospedale Cardarelli (Naples, Italy), for the useful suggestions.

Authors' Contribution The Author had full access to all the data in the study and take responsibility for the integrity of the data and the accuracy of the data analysis. The Author performed: study concept and design, acquisition of data, analysis and interpretation of data, drafting of the manuscript, critical revision of the manuscript for important intellectual content, statistical analysis, obtained funding, administrative, technical, and material support, study supervision.

\section{Declarations}

The author warrants that the article is original, does not infringe on any copyright or other proprietary right of any third part, is not under consideration by another journal, and has not been previously published.

Conflict of Interest The Author does not have any known or potential conflict of interest including any financial, personal or other relationships with other people or organizations within three years of beginning the submitted work that could inappropriately influence, or be perceived to influence, their work.

Human and Animal Rights and Informed Consent This research does not contain any studies with human participants or animals performed by the Author.

\section{References}

Ackerman, R. (1961). Inductive simplicity. Philosophy of Science, 28, 162-171.

Akaike, H. (1973). Information theory and the extension of the maximum likelihood principle. In B. Petrov \& F. Csaki (Eds.), Second International Symposium on Information Theory. Akademiai Kiado.

Andreu-Moreno, I., \& Sanjuán R. (2020). Collective viral spread mediated by virion aggregates promotes the evolution of defective interfering particles. mBio, 11(1). https://doi.org/10.1128/mBio.02156-19.

Appenzeller-Herzog, C., \& Hauri, H.-P. (2006). The ER-Golgi intermediate compartment (ERGIC): In search of its identity and function. Journal of Cell Science, 2006(119), 2173-2183. https://doi.org/ $10.1242 /$ jcs.03019.

Badiou, A. (1888). Being and event. Bloomsbury, London (2015).

Baker, A. (2003). Quantitative parsimony and explanatory power. British Journal for the Philosophy of Science, 54, 245-259.

Barnes, E. C. (2000). Ockham's razor and the anti-superfluity principle. Erkenntnis, 53, 353-374.

Bechtel, W. (2008). Mental Mechanisms: Philosophical Perspectives on Cognitive Neuroscience. Lawrence Erlbaum Associates. ISBN: 978-0-8058-6333-8.

Bellmund, L. S., Gärdenfors, P., Moser, E. I., \& Doeller, C. F. (2018). Navigating cognition: Spatial codes for human thinking. Science, 362(6415), eaat6766. https://doi.org/10.1126/science.aat6766.

Bhowmik, S., \& Krishnamurthy, R. (2019). The role of sugar-backbone heterogeneity and chimeras in the simultaneous emergence of RNA and DNA. Nature Chemistry, 11, 1009-1018. 
Bobrovskiy, I., Hope, J. M., Ivantsov, A., Nettersheim, B. J., Hallmann, C., \& Brocks, J. J. (2018). Ancient steroids establish the Ediacaran fossil Dickinsonia as one of the earliest animals. Science., 361(6408), 1246-1249. https://doi.org/10.1126/science.aat7228.

Bong, K.-W., Utreras-Alarcón, A., Ghafari, F., Liang, Y.-C., Tischler, N. et al. (2020). A strong no-go theorem on the Wigner's friend paradox. Nature Physics, 16, 1199-1205.

Brian D.A., Baric R.S. 2005. Coronavirus Genome Structure and Replication. In: Enjuanes L. (eds) Coronavirus Replication and Reverse Genetics. Current Topics in Microbiology and Immunology, vol 287. Springer.

Brown, M. K., \& Naidoo, N. (2012). The endoplasmic reticulum stress response in aging and age-related diseases. Frontiers in Physiology, 3, 263. https://doi.org/10.3389/fphys.2012.00263.

Budday S, Sommer G, .Haybaeck J, Steinmann P, Holzapfel GA, Kuhl E. 2017. Rheological characterization of human brain tissue. Acta Biomaterialia, 60, 315-329. https://doi.org/10.1016/j.actbio.2017. 06.024.

Bunge, M. (1961). The weight of simplicity in the construction and assaying of scientific theories. Philosophy of Science, 28, 162-171.

Calvo-Rodríguez, M., García-Durillo, M., Villalobos, C., \& Núñez, L. (2016). In vitro aging promotes endoplasmic reticulum (ER)-mitochondria Ca $2+$ cross talk and loss of store-operated Ca $2+$ entry (SOCE) in rat hippocampal neurons. Biochimica et Biophysica Acta, 1863(11), 2637-2649. https:// doi.org/10.1016/j.bbamcr.2016.08.001.

Chadwick, S. R., \& Lajoie, P. (2019). Endoplasmic reticulum stress coping mechanisms and lifespan regulation in health and diseases. Frontiers in Cell and Development Biology, 7, 84. https://doi.org/10. 3389/fcell.2019.00084.

Chamberlain, B.P., Clough, J., Deisenroth, M.P. (2017). Neural Embeddings of Graphs in Hyperbolic Space. arXiv:1705.10359.

Chater, N. (1999). The search for simplicity: A fundamental cognitive principle. The Quarterly Journal of Experimental Psychology, 52A, 273-302.

Chen, J., Quiles-Puchalt, N., Chiang, Y. N., Bacigalupe, R., Fillol-Salom, A., et al. (2018). Genome hypermobility by lateral transduction. Science, 362(6411), 207-212. https://doi.org/10.1126/scien ce.aat5867.

Chen, Y., Liu, Q., \& Guo, D. (2020). Emerging coronaviruses: Genome structure, replication, and pathogenesis. Journal of Medical Virology, 92(4), 418-423. https://doi.org/10.1002/jmv.25681.

Cho, J.-H., Saini, D. K., Karunarathne, W. K. A., Kalyanaraman, V., \& Gautam, N. (2011). Alteration of Golgi structure in senescent cells and its regulation by a $\mathrm{G}$ protein $\gamma$ subunit. Cellular Signalling, 23(5), 785-793. https://doi.org/10.1016/j.cellsig.2011.01.001.

D’Angiolo, M., De Chiara, M., Yue, J. X., Irizar, A., Stenberg, S., et al. (2020). A yeast living ancestor reveals the origin of genomic introgressions. Nature, 587, 420-425. https://doi.org/10.1038/ s41586-020-2889-1.

Dal, P. M. (1956). la teoria del "significato totale" della proposizione nel pensiero di Gregorio da Rimini. Rivista Critica di Storia della Filosofia, 11(3/4), 287-311.

de Haan, C. A., \& Rottier, P. J. M. (2006, 2006). Hosting the severe acute respiratory syndrome coronavirus: Specific cell factors required for infection. Cellular Microbiology. https://doi.org/10.1111/j. 1462-5822.2006.00744.x.

Del Giudice, F., Tassieri, M., Oelschlaeger, C., \& Shen, A. Q. (2017). When microrheology, bulk rheology, and microfluidics meet: Broadband rheology of hydroxyethyl cellulose water solutions. Macromolecules, 50(7), 2951-2963. https://doi.org/10.1021/acs.macromol.6b02727.

Deleuze, G., Guattari, F. ( 1980). A Thousand Plateaus: Capitalism and Schizophrenia. Ed. Bloomsbury Publishing PLC, 1988, EAN: 9780485113358.

Despres, J., Ramdani, Y., di Giovanni, M., Bénard, M., Zahid, A., et al. (2019). Replicative senescence of human dermal fibroblasts affects structural and functional aspects of the Golgi apparatus. Experimental Dermatology, 28(8), 922-932. https://doi.org/10.1111/exd.13886.

Ehre, C. (2020). SARS-CoV-2 infection of airway cells. The New England Journal of Medicine, 383, 969. https://doi.org/10.1056/NEJMicm2023328.

ElSheikh M, Arani A, Perry A, Boeve BF, Meyer FB, 2017 et al. MR Elastography demonstrates unique regional brain stiffness patterns in dementias. AJR. American Journal of Roentgenology 209(2):403408. https://doi.org/10.2214/AJR.16.17455.

Forster, M., \& Sober, E. (1994). How to tell when simpler, more unified, or less ad hoc theories will provide more accurate predictions. British Journal for the Philosophy of Science, 45, 1-35. 
Foster, M., \& Martin, M. (1966). Probability, confirmation, and simplicity: Readings in the philosophy of inductive logic. The Odyssey Press.

Friedman, M. (1974). Explanation and scientific understanding. Journal of Philosophy, LXXI, 1-19.

Friston, K. (2010). The free-energy principle: A unified brain theory? Nature Reviews. Neuroscience, 11(2), 127-138.

Fu, L., Steinhardt, W., Zhao, H., Socolar, J. E. S., \& Charbonneau, P. (2016). Hard sphere packings within cylinders. Soft matter. Royal Society of Chemistry, 12(9), 2505-2514.

Gerischer LM, Fehlner A, Köbe T, Prehn K, Antonenko D, 2017 et al. Combining viscoelasticity, diffusivity and volume of the hippocampus for the diagnosis of Alzheimer's disease based on magnetic resonance imaging. Neuroimage Clin. 18:485-493. https://doi.org/10.1016/j.nicl.2017.12.023.

Gibbons, A. (2017). Neandertals mated early with modern humans. Science, 357(6346), 14. https://doi. org/10.1126/science.357.6346.14.

Goodman, N. (1959). Recent developments in the theory of simplicity. Philosophy and Phenomenological Research, 19, 429-446.

Harman, G. (1999). Simplicity as a pragmatic criterion for deciding what hypotheses to take seriously. In G. Harman (Ed.), Reasoning, meaning and mind. Oxford University Press.

Hesse, M. (1974). The structure of scientific inference. Macmillan.

Hipolito, I. (2019). A simple theory of every 'thing'. Physics of Life Reviews. https://doi.org/10.1016/j. plrev.2019.10.006.

Hofstadter, D., Sander, E. (2011). Surfaces and Essences: Analogy as the Fuel and Fire of Thinking. Basic Books.

Ivantsov, A. Y. (2007). Small Vendian transversely articulated fossils. Paleontological Journal., 41(2), 113-122. https://doi.org/10.1134/S0031030107020013.

Janikiewicz, J., Szymański, J., Malinska, D., Patalas-Krawczyk, P., Michalska, B., et al. (2018). Mitochondria-associated membranes in aging and senescence: Structure, function, and dynamics. Cell Death \& Disease, 9(3), 332. https://doi.org/10.1038/s41419-017-0105-5.

Ke, Z., Oton, J., Qu, K., Cortese, M., Zila, V., et al. (2020). Structures and distributions of SARS-CoV-2 spike proteins on intact virions. Nature. https://doi.org/10.1038/s41586-020-2665-2.

Kelly, K. (2004). Justification as truth-finding efficiency: How Ockham's razor works. Minds and Machines, 14, 485-505.

Koczkodaj, W. W., Magnot, J.-P., Mazurek, J., Peters, J. F., Rakhshani, H., Soltys, M., Strzałka, D., Szybowski, J., \& Tozzi, A. (2017). On normalization of inconsistency indicators in pairwise comparisons. International Journal of Approximate Reasoning., 86, 73-79. https://doi.org/10.1016/j.ijar. 2017.04.005.

Leeks, A., Sanjuán, R., \& West, S. A. (2019). The evolution of collective infectious units in viruses. Virus Research, 265, 94-101. https://doi.org/10.1016/j.virusres.2019.03.013.

Lin, Y., Yan, X., Cao, W., Wang, C., Feng, J., et al. (2004). Probing the structure of the SARS coronavirus using scanning electron microscopy. Antiviral Therapy, 9(2), 287-289.

Liu, L., Wang, J., Feng, J., Yao, M., Hao, C., et al. (2018). Serum Golgi protein 73 is a marker comparable to APRI for diagnosing significant fibrosis in children with liver disease. Scientific Reports, 8(1), 16730. https://doi.org/10.1038/s41598-018-34714-y.

Lu, Z., \& Raz, O. (2017). Nonequilibrium thermodynamics of the Markovian Mpemba effect and its inverse. PNAS, 114(20), 5083-5088.

Massilani, D., Skov, L., Hajdinjak, M., Gunchinsuren, B., Tseveendorj, D., et al. (2020). Denisovan ancestry and population history of early east Asians. Science, 370(6516), 579-583. https://doi.org/ 10.1126/science.abc1166.

McGinn, C. (1994). The problem of philosophy. Philosophical Studies, 76(2-3), 133-156. https://doi.org/ 10.1007/bf00989821.

Miceli, S., Ness, T. V., Einevoll, G. T., \& Schubert, D. (2017). Impedance Spectrum in cortical tissue: Implications for propagation of LFP signals on the microscopic level. eNeuro, 4(1). https://doi.org/ 10.1523/ENEURO.0291-16.2016.

Millen, S., Gross, C., Donhauser, N., Mann, M. C., Péloponèse Jr., J. M., \& Thoma-Kress, A. K. (2019). Collagen IV (COL4A1, COL4A2), a component of the viral biofilm, is induced by the HTLV-1 Oncoprotein tax and impacts virus transmission. Frontiers in Microbiology, 10, 2439. https://doi. org/10.3389/fmicb.2019.02439.

Moreva, E.V., Brida, G. Gramegna, M., Giovannetti, V. (2014). Entanglement discloses Time as an emergent phenomenon. 2014 Conference: CLEO: QELS_Fundamental Science. https://doi.org/10.1364/ CLEO_QELS.2014.FW1A.8. 
Murphy, M. C., Huston III, J., Jack Jr., C. R., Glaser, K. J., Manduca, A., et al. (2011). Decreased brain stiffness in Alzheimer's disease determined by magnetic resonance elastography. J MagnReson Imaging., 34(3), 494-498. https://doi.org/10.1002/jmri.22707.

Nannini, A. (2015). Pierre Ceffons di Clairvaux. La questione dei significabilia complexe intorno al 1350. I. Edizione della quaestio 25 della Lectura super I Sententiarum. Rivista Di Filosofia Neo-Scolastica $-2015-4$.

Ockham, W. (1991). Quodlibetal questions. Eds. Freddoso AJ, Kelley FE. Yale University Press.

Ogilvie, G. I., \& Proctor, M. R. E. (2003). On the relation between viscoelastic and magnetohydrodynamic flows and their instabilities. Journal of Fluid Mechanics, 476, 389-409. https://doi.org/10. 1017/S0022112002003051.

Oreskes, N., Shrader-Frechette, K., \& Belitz, K. (1994). Verification, validation, and confirmation of numerical models in the earth sciences. Science, 263, 641-646.

Parri, N., Lenge, M., \& Buonsenso, D. (2020). Children with Covid-19 in pediatric emergency departments in Italy. NEJM. https://doi.org/10.1056/NEJMc2007617.

Proietti, M., Pickston, A., Graffitti, F., Barrow, P., Kundys, D., et al. (2019). Experimental test of local observer independence. Science Advances, 5(9), eaaw9832. https://doi.org/10.1126/sciadv.aaw9832.

Qiu, H., Wu, J., Hong, L., Luo, Y., Song, Q., \& Chen, D. (2020). Clinical and epidemiological features of 36 children with coronavirus disease 2019 (COVID-19) in Zhejiang, China: An observational cohort study. The Lancet Infectious Disease. https://doi.org/10.1016/S1473-3099(20)30198-5.

Ranta, R., Le Cam, S., Tyvaert, L., \& Louis-Dorr, V. (2017). Assessing human brain impedance using simultaneous surface and intracerebral recordings. Neuroscience, 343.

Risco, C., Rodríguez, J. R., López-Iglesias, C., Carrascosa, J. L., Esteban, M., \& Rodríguez, D. (2002). Endoplasmic reticulum-Golgi intermediate compartment membranes and vimentin filaments participate in vaccinia virus assembly. Journal of Virology, 76(4), 1839-1855.

Segredo-Otero, E., \& Sanjuán, R. (2019). The effect of genetic complementation on the fitness and diversity of viruses spreading as collective infectious units. Virus Research, 267, 41-48. https://doi.org/ 10.1016/j.virusres.2019.05.005.

Sengupta, B., Tozzi, A., Coray, G. K., Douglas, P. K., \& Friston, K. J. (2016). Towards a neuronal gauge theory. PLOS Biology, 14(3), e1002400. https://doi.org/10.1371/journal.pbio.1002400.

Shaltiel-Karyo, R., Frenkel-Pinter, M., Rockenstein, E., Patrick, C., Levy-Sakin, M., et al. (2013). A blood-brain barrier (BBB) disrupter is also a potent $\alpha$-synuclein ( $\alpha$-syn) aggregation inhibitor: A novel dual mechanism of mannitol for the treatment of Parkinson disease (PD). The Journal of Biological Chemistry, 288(24), 17579-17588. https://doi.org/10.1074/jbc.M112.434787.

Shamaev, A. S., \& Shumilova, V. V. (2018). Calculation of natural frequencies and damping coefficients of a multi-layered composite using homogenization theory. IFAC-PapersOnLine, 51(2), 126-131. https://doi.org/10.1016/j.ifacol.2018.03.022.

Slon, V., Mafessoni, F., Vernot, B., de Filippo, C., Grote, S., et al. (2018). The genome of the offspring of a Neanderthal mother and a Denisovan father. Nature, 561, 113-116.

Smerlak, M., \& Rovelli, C. (2007). Relational EPR. Foundations of Physics, 37, 427-445.

Sowa, J. F., \& Majumdar, A. K. (2003). Analogicalal reasoning. Conceptual structures for knowledge creation and communication, proceedings of ICCS 2003. Springer-Verlag.

Spade, P. V. (1972). The unity of a science according to Peter Auriol. Franciscan Studies, 32, $203-217$.

Su, Y., Wang, P., Shen, H., Sun, Z., Xu, C., et al. (2018). The protein kinase D1-mediated classical protein secretory pathway regulates the Ras oncogene-induced senescence response. Journal of Cell Science, 131(6), jcs207217. https://doi.org/10.1242/jcs.207217.

Sylla, E. D. (1998a). God, indivisibles, and logic in the later middle ages: Adam Wodeham's response to Henry of Harclay. Medieval Philosophy and Theology, 7(1998), 69-87.

Sylla, D. E. (1998b). God, indivisibles, and logic in the later middle ages: Adam Wodeham's response to Henry of Harclay. Medieval Philosophy and Theology, 7(1), 69-87.

Teich, E. G., et al. (2016). 'Clusters of polyhedra in spherical confinement', proceedings of the National Academy of Sciences. National Acad Sciences, 113(6), E669-E678.

The BIG Bell Test Collaboration. (2018). Challenging local realism with human choices. Nature, 557, 212-216.

Thoulouze, M. I., \& Alcover, A. (2011). Can viruses form biofilms? Trends in Microbiology, 19(6), 257262. https://doi.org/10.1016/j.tim.2011.03.002.

Torres-González, E., Bueno, M., Tanaka, A., Krug, L. T., \& Cheng, D.-S. (2012). Role of endoplasmic reticulum stress in age-related susceptibility to lung fibrosis. American Journal of Respiratory Cell and Molecular Biology, 46(6), 748-756. https://doi.org/10.1165/rcmb.2011-0224OC. 
Tozzi, A. (2015). Information processing in the CNS: A Supramolecular chemistry? Cognitive Neurodynamics, 9(5), 463-477.

Tozzi, A. (2019). The multidimensional brain. Physics of Life Reviews, 31, 86-103. https://doi.org/10. 1016/j.plrev.2018.12.004.

Tozzi, A., \& Peters, J. F. (2018). What it is like to be "the same"? Progress in Biophysics and Molecular Biology., 133, 30-35. https://doi.org/10.1016/j.pbiomolbio.2017.10.005.

Tozzi, A., \& Peters, J. F. (2020a). Removing uncertainty in neural networks. Cognitive Neurodynamics, 14, 339-345. https://doi.org/10.1007/s11571-020-09574-w.

Tozzi, A., \& Peters, J. F. (2020b). A topological approach to infinity in physics and biophysics. Foundations of Science. https://doi.org/10.1007/s10699-020-09674-0.

Turalska, M., \& West, B. J. (2018). Fractional dynamics of individuals in complex networks. Frontiers of Physics, 6, 110. https://doi.org/10.3389/fphy.2018.00110.

Turoňová, B., Sikora, M., Schürmann, C., Hagen, W. J. H., Welsch, S., et al. (2020). In situ structural analysis of SARS-CoV-2 spike reveals flexibility mediated by three hinges. Science. https://doi.org/ 10.1126/science.abd5223.

Udono, M., Fujii, K., Harada, G., Tsuzuki, Y., Kadooka, K., et al. (2015). Impaired ATP6V0A2 expression contributes to Golgi dispersion and glycosylation changes in senescent cells. Scientific Reports, 5, 17342 .

Waninger, S., Ahlfors, S., Stikic, M., Korszen, S., Berka, C., et al. (2016). Identification of neurophysiological biomarkers of mci using resting state EEG. Alzheimer \& Dementia, 12(7, Supplement), P882. https://doi.org/10.1016/j.jalz.2016.06.1823.

Watanabe, Y., Allen, J. D., Wrapp, D., McLellan, J. S., \& Crispin, M. (2020). Site-specific glycan analysis of the SARS-CoV-2 spike. Science, 369(6501), 330-333. https://doi.org/10.1126/science.abb99 83.

Yang, J. M. (2018). A relational formulation of quantum mechanics. Scientific Reports, 8, 13305.

Zupko, J. (1994). How it played in the rue de Fouar re: The reception of Adam wodeham's theory of the _Complexe Significable_ in the arts faculty at Paris in the mid-fourteenth century. Franciscan Studies, 54(1), 211-225.

Publisher's Note Springer Nature remains neutral with regard to jurisdictional claims in published maps and institutional affiliations. 